\title{
Effects of Commercial Yeast Probiotic (Antox® Supplement) On Broiler Chickens Growth Performance and Salmonella Inhibition
}

\author{
I.O Olatoye ${ }^{1,2}$, R.C Okocha ${ }^{1}$, P.M Olumide ${ }^{1}$ \\ ${ }^{I}$ Department of Veterinary Public Health and Preventive Medicine, University of Ibadan, Ibadan Nigeria \\ ${ }^{2}$ School for Global Animal Health, Washington State University, WA, USA
}

\begin{abstract}
The extensive use of antibiotics in livestock has contributed to the development of antibiotics resistant bacteria and residue deposition in food of animal origin. Alternative to antibiotics use for animal health and welfare as well as food safety is essential for global antibiotic resistance control. The effect of a commercially available monoculture yeast probiotics (Antox $\left.{ }^{\circledR}\right)$ on the growth performance and inhibition of gut salmonella was carried out in this study. One hundred, one- day-old broiler chicks were randomly distributed into four groups for dosing of a probiotic (containing Saccharomyces cerevisiae) and inoculation with Salmonella gallinarum. The chickens were grouped into four vis: Group 1(control): not dosed with Antox ${ }^{\circledR}$ and not inoculated with Salmonella; Group 2: dosed with Antox ${ }^{\circledR}$ and inoculated with Salmonella; Group 3: dosed with Antox ${ }^{\circledR}$ only; Group 4: inoculated with Salmonella only. The growth performance of the chickens, feed intake (FI) and feed conversion rate (FCR) were monitored weekly throughout the experiment. This study showed improved growth performance of the chicken in live and carcass weight as well as reduced caecal Salmonella load by the yeast probiotic. Probiotic group had significantly $(p<0.01)$ higher body weights compared to the control and Salmonella groups. FI was significantly $(p<0.05)$ higher in the probiotic group, and significant $(p<0.01)$ different from the control and Salmonella infected groups. Higher FCR was recorded in the control group than in probiotic-supplemented groups. Also the caecal Salmonella load of the probiotic group $\left(2.404 \log _{10} c f u / g\right)$ was significantly lower $(p<0.001)$ than in the Salmonella infected groups. This study confirmed that yeast probiotic improved body weight, feed intake, better feed conversion ratio in broiler chickens and also effectively inhibited the colonization of ceacal salmonella. Its application can replace the use of antibiotics as growth promoters and reduce the incidence of Salmonella and antibiotic resistance in poultry and should be promoted for adoption by commercial poultry farms.
\end{abstract}

Key words: Broiler chickens, growth performance, probiotic and salmonella inhibition

\section{Introduction}

Poultry represents nearly $33 \%$ of global meat production and is a source of protein that plays an important role in human nutrition (FAO, 2010). Modern intensive poultry production produces market ready broiler chickens within six weeks of their age. This achievement arose from improved productivity via genetic selection, improved feeding and health management practices involving usage of antibiotics as therapeutic agents to treat bacterial diseases and as feed additives for growth promotion (Apata et al., 2011).

Salmonellosis is one of the most commonly and widely distributed foodborne diseases globally. This disease in the past has caused tremendous cost to society in many countries worldwide. About 2 to 4 million of cases have been reported annually and yet a significant number of cases have been unreported worldwide. It is one of the most widespread zoonosis throughout the world, and human infections are often associated with the consumption of contaminated poultry products (Hang'ombe et al., 1999). Salmonella contamination is a major problem in the poultry industry because poultry is a major source of animal protein for man.

The extensive use of antibiotics to enhance performance or control diseases, including Salmonellosis in poultry, has contributed to the development of antibiotics resistant bacteria and residue deposition in food of animal origin. In Nigerian poultry production, antibiotics are routinely use in feed water and parenterally for prevention and treatment of infectious disease as well as for growth promotion. More so, indiscriminate and unregulated use of antibiotics are reported common practice in poultry production in Nigeria (Kabir et al., 2004; Olatoye, 2012). Increasing global threat of antibiotic resistance and residues has resulted in quests for alternative measures that reduce the dependence on antibiotics for food animal production. The use of antibiotics as growth promoters was completely banned in 1999 by the European Union (EU) (European Commision, 2001). This was due to increasing microbial resistance to antibiotics and residues in chicken meat products which might be harmful to consumers.

Currently, in many parts of the world, feed additives, such as probiotics are being adopted to alleviate the problems associated with the withdrawal of antibiotics from feed. Probiotic is defined as "a live microbial feed supplement which beneficially affects the host animal by improving its intestinal microbial balance" (Fuller,1989). Probiotics are biological products, which stimulate the immunity system and increase its 
defensive activity against pathogenic bacteria. Probiotics competitively exclude the Salmonella bacteria from the intestinal tract of the treated chickens. The auspicious effect of probiotics over the organism is due to the better adhesion of the lactic acid bacteria to the intestinal epithelium in comparison to the pathogenic bacteria, and stopping the implementation of those bacteria over the mucosa of the intestine (Bonomi et al., 1978) They are increasingly being used as alternative to improve intestinal microflora balance (Fuller, 1989) and also improve welfare, enhance food safety but have not been widely adopted in Nigerian poultry industry.

This study investigated the efficacy of Antox $\AA$, a commercially available monoculture yeast probiotics (containing Saccharomyces cerevisiae $(4.125 \log 106 \mathrm{cfu})$ on the growth performance and inhibition of gut Salmonella in broiler chickens.

\section{Chicks and management:}

\section{Materials and methods}

One hundred, one-day old Arbor-Acres ${ }^{\circledR}$ breed of broiler chicks were purchased from commercial hatchery. The birds were housed in biosecurity controlled poultry pen with the floor covered with wood shavings. Feed (as shown in Table 1) and water were given ad libitum. Brooding temperature was maintained for proper heating and reduced after brooding was completed. The chickens were randomly distributed into four groups for dosing of a probiotic (containing Saccharomyces cerevisiae $\left(4.125 \times 10^{6} \mathrm{cfu}\right.$ ) and inoculation with Salmonella gallinarum. The birds were grouped into four vis: Group 1(control): not dosed with Antox ${ }^{\circledR}$ and not inoculated with Salmonella; Group 2: dosed with Antox ${ }^{\circledR}$ and inoculated with Salmonella; Group 3: dosed with Antox ${ }^{\circledR}$ only; Group 4: inoculated with Salmonella only.

\section{Chicks performance:}

The growth performance of the chickens through; weekly weight gain, feed intake (FI) and feed conversion (FCR) were monitored weekly throughout the experiment. Mortality record was also taken.

\section{Relative organs weight:}

Survivor chicken in all groups were humanely slaughtered at the end of the experiment, and carcass, gizzard, liver, spleen and heart were collected, and the mean weight were recorded.The caecum of each chicken was also observed and the mean caecal load was determined.

Table 1: Composition of the broiler starter feed ingredients $(100 \mathrm{~kg})$

\begin{tabular}{|l|l|}
\hline Ingredients & Weight $(\mathrm{kg})$ \\
\hline Maize & 57.00 \\
\hline Soybean meal & 30.00 \\
\hline Wheat offal & 5.00 \\
\hline Fish meal (72\%) & 2.00 \\
\hline Vitamin premix & 0.25 \\
\hline L-lysine HCl(98\%) & 0.15 \\
\hline DL-methionine(99\%) & 0.10 \\
\hline Bone meal & 1.55 \\
\hline Oyster shell & 3.50 \\
\hline Choline-Cl $(50 \%)$ & 0.10 \\
\hline Salt & 0.35 \\
\hline Total & 100.00 \\
\hline
\end{tabular}

\section{Preparation of Agar for Culturing and Isolation of Salmonella gallinarum:}

The following culture media were used for isolation: selenite-F broth, peptone water, nutrient broth, MacConkey agar, XLT 4 agar, Salmonella-Shigella agar and nutrient agar prepared according to manufacturers' recommendations.

\section{Preparation of Salmonella gallinarum for Inoculation:}

Pure culture of Salmonella gallinarum isolate was obtained, isolated from laboratory was enriched in peptone water at $37^{\circ} \mathrm{C}$ overnight, and sub-cultured unto Salmonella - Shigella agar and incubated for 18-24 hours. After which single colonies were inoculated into nutrient broth and incubated for 8-18hours. This was used to inoculate Salmonella infected groups of chickens (Group 2 and 4) orally at three weeks of age.

\section{Bacterial isolation from inoculated chicken:}

At six weeks the caecal contents from each group were collected aseptically and were enriched in peptone water overnight at $37^{\circ} \mathrm{C}$. Test tubes were filled with $9 \mathrm{ml}$ of peptone water and $1 \mathrm{ml}$ of sample (caecal content) enriched with Selenite-F broth was added. A 5 fold serial dilution was done from which plating was 
done. The next day a 5 fold dilution was done and plated to count the caecal Salmonella load of each group $\left(\log _{10} \mathrm{cfu} / \mathrm{g}\right)$

\section{Statistical analysis:}

Data collected were computed into means and standard deviation. The data was also subjected to the analysis of variance using Graphpad Prism statistical software (GraphPad Software Inc, USA). All statements of differences were based on significance of $\mathrm{P}<0.05$.

\section{Results}

The mean live weights (in grams) of the broilers experimentally dosed and inoculated with or without Antox ${ }^{\circledR}$ and Salmonella are presented in Table 2. In all the groups, a general increase in weght was observed during the six weeks of the experiment. There was no significant difference in the mean weights in all the groups until week 2. At week 2, Group 3 had lower mean weight (301.50 \pm 47.71 ) compared to other groups which had the same mean weight $(336.00 \pm 32.39)$. However, at week 6 , group 3 eventually had the highest value

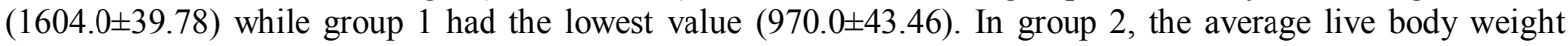
(336.0g) was significantly higher $(\mathrm{p}=0.0495)$ than group $3(301.5 \mathrm{~g})$ during the first two weeks of life. However, at week 3 , the average live body weight of Group $3(481.8 \mathrm{~g})$ was significantly higher $(\mathrm{p}<0.001)$ as compared to group $2(459.4 \mathrm{~g})$, group $4(424.0 \mathrm{~g})$ and group 1 (control) $(424.0 \mathrm{~g})$. The overall average live body weight of group $3(1604.0 \mathrm{~g})$ was significantly higher $(\mathrm{p}<0.001)$ throughout the experiment as compared with control group $2(1260.0 \mathrm{~g})$, Group $4(1192.0 \mathrm{~g})$ and group $1(970.0 \mathrm{~g})$.

The mean carcass and organ weights $(\mathrm{g})$ of the chickens at the end of the experiment are also presented in Table 3 . The overall average carcass weights and organ weights were significantly higher $(p<0.05)$ in group 3 than group 2, group 4 and group 1 .

The caecal Salmonella load of the different groups of birds inoculated at the end of the experiment is shown in figure 1. The caecal Salmonella load $\left(\log _{10} \mathrm{cfu} / \mathrm{g}\right)$ of Group $3(2.404)$ was significantly lower $(\mathrm{p}<0.001)$ than group 4 (2.740), group 2 (3.552) and group 1 (3.838).

By clinical examination, the chickens in groups 2 and 3 appeared healthy with good conformation without physical abnormalities throughout the experiment. While the chickens in Salmonella without Antox ${ }^{\circledR}$ (group 4) showed clinical signs of dullness, depression, anorexia, ruffled feathers, somnolence, weakness and poor weight gain. The mortality rate in the different groups are also shown in Table 2, with the highest mortality of $48 \%$ recorded in group 4 (Salmonella infected without Antox ${ }^{\circledR}$ and no mortality was recorded in group 3.

Table 2: Body weight gain, feed intake, feed conversion ratio and mortality rate in broiler chicken groups experimentally dosed with or without probiotics ( Antox®) and Salmonella

\begin{tabular}{|c|c|c|c|c|c|c|c|c|c|}
\hline \multirow{2}{*}{ Groups } & \multicolumn{6}{|c|}{ Mean Live Weight (g) } & \multirow{2}{*}{$\begin{array}{l}\text { Feed } \\
\text { intake } \\
(\mathrm{g})\end{array}$} & \multirow{2}{*}{$\begin{array}{l}\text { Feed } \\
\text { conversion } \\
\text { ratio } \\
(\mathrm{g} / \mathrm{g})\end{array}$} & \multirow{2}{*}{$\begin{array}{l}\text { Mortality } \\
(\%)\end{array}$} \\
\hline & Week 1 & Week 2 & Week 3 & Week 4 & Week 5 & Week 6 & & & \\
\hline 1 & $194 \pm 40.06$ & $336 \pm 32.39$ & $424 \pm 53.67$ & $597.8 \pm 118.50$ & $762.10 \pm 143.30$ & $970 \pm 43.46$ & $\begin{array}{l}1360.9 \pm 14 \\
.2\end{array}$ & $\begin{array}{l}1.403 \pm 0.01 \\
12\end{array}$ & 20.0 \\
\hline 2 & $194 \pm 40.06$ & $336 \pm 32.39$ & $459.4 \pm 76.67$ & $712 \pm 120.50$ & $915 \pm 152.90$ & $\begin{array}{l}1260 \pm 80.5 \\
5\end{array}$ & $1764 \pm 15.3$ & $\begin{array}{l}1.402 \pm 0.01 \\
03\end{array}$ & 4.0 \\
\hline 3 & $194 \pm 40.06$ & $301.5 \pm 47.71$ & $481.8 \pm 85.77$ & $810.5 \pm 115.10$ & $985.0 \pm 198.20$ & $\begin{array}{l}1604 \pm 39.7 \\
8\end{array}$ & $\begin{array}{l}2149.23 \pm 1 \\
2.5\end{array}$ & $\begin{array}{l}1.390 \pm 0.11 \\
5\end{array}$ & 0.0 \\
\hline 4 & $194 \pm 40.06$ & $336 \pm 32.39$ & $424 \pm 53.67$ & $642 \pm 159.9$ & $864 \pm 191.60$ & $\begin{array}{l}1192 \pm 52.6 \\
6\end{array}$ & $\begin{array}{l}1698.6 \pm 18 \\
.1\end{array}$ & $\begin{array}{l}1.425 \pm 0.10 \\
6\end{array}$ & 48.0 \\
\hline
\end{tabular}

Table 2: Mean carcass and organ weight (g) of broilers fed with and without Salmonella and Antox®

\begin{tabular}{|l|l|l|l|l|l|}
\hline & CARCASS & GIZZARD & LIVER & SPLEEN & HEART \\
\hline GROUP 1 & $375.7 \pm 38.25^{\mathrm{a}}$ & $26.95 \pm 6.010^{\mathrm{d}}$ & $16.30 \pm 8.061^{\mathrm{e}}$ & $0.600 \pm 0.2828^{\mathrm{h}}$ & $3.600 \pm 0.9899^{\mathrm{j}}$ \\
\hline GROUP 2 & $581 \pm 57.98^{\mathrm{a}}$ & $44.10 \pm 6.788^{\mathrm{d}}$ & $18.10 \pm 0.9899^{\mathrm{f}}$ & $1.050 \pm 0.2121^{\mathrm{h}}$ & $4.400 \pm 1.131^{\mathrm{j}}$ \\
\hline GROUP 3 & $942 \pm 56.57^{\mathrm{a}}$ & $59.30 \pm 6.031^{\mathrm{c}}$ & $21.05 \pm 3.889^{\mathrm{e}}$ & $1.300 \pm 01414^{\mathrm{g}}$ & $5.950 \pm 0.3536^{\mathrm{i}}$ \\
\hline GROUP 4 & $492.0 \pm 132.1^{\mathrm{b}}$ & $31.95 \pm 10.39^{\mathrm{d}}$ & $17.65 \pm 4.596^{\mathrm{e}}$ & $0.800 \pm 0.00$ & $2.450 \pm 0.3536^{\mathrm{j}}$ \\
\hline
\end{tabular}

$\mathrm{p} \leq 0.05$ (a-j means differ significantly from each other) 


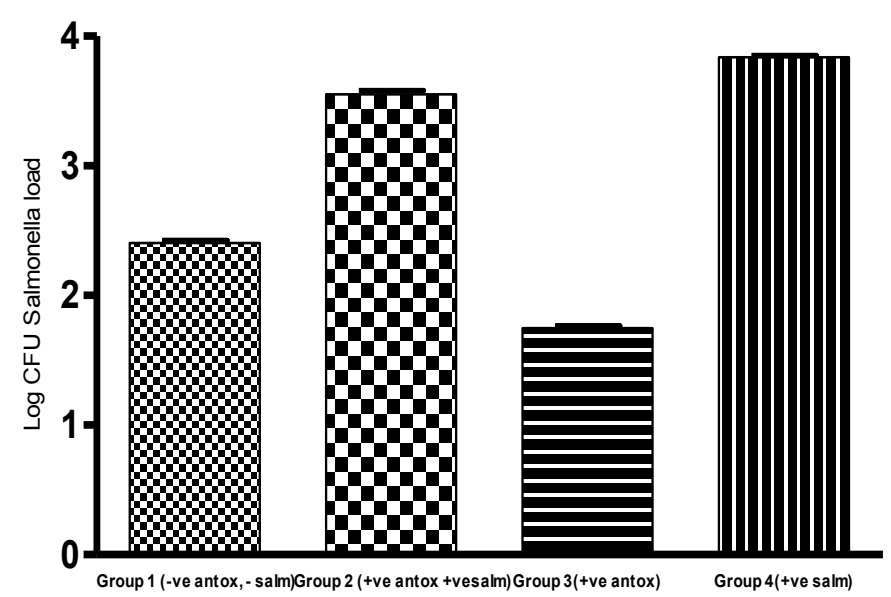

Figure 1: Mean ceacal Salmonella load of chicken (logCFU) 30 post infection

\section{Discussion}

Antox ${ }^{\circledR}$ is a biological product equipped with probiotics: Saccharomyces cerevisiae (SC)), and prebiotics: Mannan oligosaccharides (MOS), gut acidifiers, amino acids and a synergistic combination of trace elements. The product has been reported to be a suitable replacement for various antibiotic growth promoters and toxin binders (Jin et al., 1997; Spring et al., 2000)

This study showed that the chicken dosed with Antox ${ }^{\circledR}$ only (group 3) have the highest growth performance and overall value of the broiler chickens in term of live, carcass and organ weight as shown in Tables 2 and 3. Also, there was a better feed conversion ratio in this group that in other groups birds. These results are similar to the findings of Miles and Bootwalla, 1991; Madrigal et al., 1993; Bradley et al., 1994; Santin et al., 2001. Also in agreement with our study, Onifade et al. [19] reported that SC improved feed/gain ratio and body weight gain.This shows efficient nutrient utilization resultant effect of Antox ${ }^{\circledR}$ supplement by reducing intestinal pathogens and improving gut absorption of nutrient.

Comparing the chickens in groups 2 and 4 both of which were challenged with Salmonella in Tables 2, the overall mean weight gain showed that Antox ${ }^{\circledR}$ reduced the effect of Salmonella on the growth and organ weight of the birds. In addition, the mortality up to $48 \%$ recorded from the Salmonella group (group 4) that was higher than those inoculated with Salmonella and supplemented with Antox ${ }^{\circledR}$ (group 2) indicated prophylactic efficacy of the supplement. This could be due to biological action of MOS selectively preventing pathogen colonization of gastro intestinal tract by offering competitive binding sites for undesirable micro organisms including Salmonella and Escherichia coli (Newman, 1994). MOS is also believed to stimulate the animal's immune system, thereby further reducing the risk of disease (Firon et al., 1983). Oyofo et al. (1989) observed that the adherence of Salmonella typhimurium to enterocytes of the small intestine of chicks, in vitro, was inhibited in the presence of mannose.

It is also noteworthy that chickens in group 1 and group 3 that were not inoculated yielded some loads of Salmonella after the experiment. This may be attributed to a colonisation by bacteria from the mother (vertically transmitted) or from the environment. The difference in the Salmonella load between group 2 and 4 could be attributed to the effect of Antox ${ }^{\circledR}$.

\section{Conclusion}

This study confirmed that the yeast probiotic (Antox $\AA$ ) improves body weight, feed intake, better feed conversion ratio in broiler chickens and also effectively inhibit the colonization of ceacal salmonella. These agree with previous studies, Mountzouris et al. $(2007 ; 2009)$ reported the beneficial effects of probiotics in promoting broiler growth, modulating cecal microflora composition and metabolic activity and reducing Salmonella burden in broilers. Therefore, administration of probiotics such as Antox ${ }^{\circledR}$ should be can reduce or replace the use of antibiotics as growth promoters and thereby reducing the incidence of Salmonella and antibiotic resistance in poultry. There is also the public health benefit of lack of residual deposition in poultry products. Therefore its use should be promoted for adoption in commercial poultry production in Nigeria where there is overdependence on antibiotics. 


\section{Acknowledgment}

The authors acknowledge Global Vetcare Nigeria Ltd for the supply of Antox ${ }^{\circledR}$ used for this study.

References

[1]. HODGETTS, B. (1981) Dealing with dirty hatching eggs. MAFF Information for Flock Farms and Hatcheries: Hatch Handout, No.17.

[2]. HODGETTS, B. (1981) Dealing with dirty hatching eggs. MAFF Information for Flock Farms and Hatcheries: Hatch Handout, No.17.

[3]. JACOB, J. and ZISWILER, V. (1982) The uropygial gland, in: FARNER, D.S., KING,S.R. \& PARKS, K.C. (Eds) Avian Biology, Vol. 6, pp. 199-324 (New York, Academic Press).

[4]. JOHNSON, R., THOMAS, F., PYM, R. and FAIRCLOUGH, R. (1986) The effect of long term genetic selection on growth hormone secretion and protein turnover in meat-type chickens. Proceedings of the 7th European Poultry Conference, Paris, pp. 975979.

[5]. LEESON, S. and SUMMERS, J.D. (1980) Production and carcass characteristics of the broiler chicken. Poultry Science 59: 786798.

[6]. SAPOLSKY, R.M., KREY, L.C. and MCEWAN, B.S. (1984) Stress down-regulates corticosterone receptor in a site-specific manner in the brain. Endocrinology 114: 287-292.

[7]. SALEH, F.I.M. (1984) Nutritional factors in relation to the stress of hot climates on the fowl. Ph. D. Thesis, University of London.

[8]. BONOMI, A., and G. VASSIA. (1978) Observations and remarks on the use of Saccharomyces cerevisiae and Kluyveromyces fragilis, in the form of living yeast, on the production and quantiqualitative characteristics of broilers. Archivio Veterinario Italiano 29:3-15.

[9]. BRADLEY, G. L., T. F. SAVAGE AND K. I. TIMM, (1994) The effects of supplementing diets with Saccharomyces cerevisiae var. boulardii on male poultry performance and ileal morphology. Poultrty Science 73: 1766-1770.

[10]. EUROPEAN COMMISION 2001. $2^{\text {nd }}$ opinion on anti-microbial resistance Available from: http://ec.europa.eu/food/fs/sc/ssc/ out203 en.pdf [cited 2009 Feb 11].

[11]. Firon $\bar{N}$, Ofek, SN. Carbohydrate specifity of the surface lectins of Esherichia coli, Klebsiella pneuomoniae and Salmonella typhimurium.Carbohydr.Res. 1983;120: 235-249.

[12]. FAO 2010. FAO Agbiz hand book of poultry meat. http://www.responsibleagroinvestment.org

[13]. Fuller R (1989). Probiotics in man and animals. J. Appl. Bacteriol., 66: 365-378.

[14]. Hang'ombe, B. M., R. M. Sharma, E. Skjerve, and L. M. Tuchili. (1999). Ocurrence of Salmonella enteritidis in pooled table eggs and market-ready chicken carcasses in Zambia. Avian Dis. 43:597.

[15]. Jin, L.Z., Ho, Y.W., Abdullah, N. and Jalaludin, S. (1997) Probiotics in poultry: modes of action. Worlds Poultry Science Jou rnal 53, 351-368.

[16]. Kabir, J., Umoh, V.J., Audu-okoh, E., Umoh, J.U. and Kwaga, J.K.P. (2004). Veterinary drug used in poultry farms and determination of antimicrobial drug residues in commercial eggs and slaughtered chicken in Kaduna State, Nigeria. Food control 15:99-105.

[17]. Madrigal, S. A., S. E. Watkins, J. T. Skinner, M. H. Adams, A. L. Waldroup and D. W. Waldroup, 1993. Effect of an active yeast culture on performance of broilers. Poult. Sci., 72 (Suppl 1), 87 (Abstr.).

[18]. Miles, R. D. and S. M. Bootwalla, 1991. Direct-Fed Microbials in Animal Production- A review of the Literature. National Feed Ingredients Association, West Des Moines, IA. Direct-fed microbials in animal production “'avian”. pp. 117-146.

[19]. 19. Newman, K., 1994. Biotechnology in the Feed Industry. Proc. Alltech's 10th Annu. Symp.. T. P. Lyons and K. A. Jacques, (eds.) Nottingham Univ. Press, Nottingham, UK. Mannan-Oligosaccharides: Natural Polymers with Significant Impact on the Gastrointestinal Microflora and the Immune System. Pp. 167-174.

[20]. Olatoye, I.O (2011), Antibiotics use and resistance patterns of Salmonella species in poultry from Ibadan, Nigeria.Trop. Vet. 29 (3): 28-35.

[21]. Oyofo B A, DeLoach JR, Corrier DE, Norman JO, Ziprin RL, Mollenhauer HH. Effect of carbohydrates on Salmonella typhimurium colonization in broiler chickens. Avian Dis. 1989;33:531-534.

[22]. Santin, E., A. Maiorka, M. Macari, M. Grecco, J. C. Sanchez, T. M. Okada and A. M. Myasaka, 2001. Performance and intestinal mucosa development of broiler chickens fed diets containing Saccharomyces cerevisiae cell wall. J. Appl. Poult. Res., 10: 236-244.

[23]. Spring P, Wenk C, Dawson KA, Newman KE. The effects of dietary mannanoligosaccharides on cecal parameters and the concentrations of enteric bacteria in the ceca of salmonella-challenged broiler chicks. Poultry Science 2000; 79:205-211. 